\title{
Marked epithelial to mesenchymal transition in surgical margins of oral cancer-an in vitro study
}

\author{
MILOS LAZAREVIC ${ }^{1}$, MAJA MILOSEVIC ${ }^{1}$, DRAGO JELOVAC ${ }^{2}$, SANJA MILENKOVIC ${ }^{3}$, \\ ZVEZDANA TEPAVCEVIC $^{4}$, FEDERICA BALDAN ${ }^{5}$, TIJANA SUBOTICKI ${ }^{6}$, BOSKO TOLJIC $^{1}$, \\ DIJANA TRISIC $^{1}$, MIROSLAV DRAGOVIC ${ }^{1}$, GIUSEPPE DAMANTE ${ }^{5}$ and JELENA MILASIN $^{1}$ \\ ${ }^{1}$ Department of Human Genetics, School of Dental Medicine, ${ }^{2}$ Clinic for Maxillofacial Surgery, \\ School of Dental Medicine, ${ }^{3}$ Department of Clinical Pathology, Clinical-Hospital Center 'Zemun', Faculty of Medicine, \\ ${ }^{4}$ Department of Pathology, School of Dental Medicine, University of Belgrade, Belgrade 11000, Serbia; \\ ${ }^{5}$ Department of Medical Area, University of Udine, I-33100 Udine, Italy; ${ }^{6}$ Department of Molecular Oncology, \\ Institute for Medical Research, University of Belgrade, Belgrade 11000, Serbia
}

Received August 28, 2019; Accepted January 17, 2020

DOI: 10.3892/ol.2020.11494

\begin{abstract}
Epithelial to mesenchymal transition (EMT) is a feature of several types of human cancer, including oral squamous cell carcinoma (OSCC). In the present study, tumor and margin cell cultures obtained from patients with OSCC were used to determine the expression patterns of certain EMT-associated markers, including vimentin, $\alpha$-smooth muscle actin, SLUG and SNAIL. In addition, other EMT-associated features, including clonal, proliferative and migratory potential were compared between the two cell types. Cell cultures were generated from tumor and margin tissue samples from 6 patients and cultured up to the fifth passage. EMT marker expression was assessed by reverse transcription-quantitative PCR. Cell proliferation, colony formation and scratch wound healing assays were conducted to characterize the two cell types in terms of proliferation rates, clonality and motility. All of the studied markers were expressed in tumor and margin cells. Although no significant differences were noted with regard to the aforementioned markers, their expression tended to be higher in margin cultures than in tumor cultures. The expressions of the EMT markers were also higher in the fifth passage compared with those noted at the first with a few exceptions. The rates of proliferation and cell migration were decreased during passages, while the number of colonies was increased in both types of cell culture. Tumor and margin cells indicated certain similarities with regard to EMT transition characteristics.
\end{abstract}

Correspondence to: Professor Jelena Milasin, Department of Human Genetics, School of Dental Medicine, University of Belgrade, Dr Subotica 8, Belgrade 11000, Serbia

E-mail: jelena.milasin@stomf.bg.ac.rs

Key words: oral cancer, epithelial to mesenchymal transition, surgical margins, gene expression, cell proliferation and migration

\section{Introduction}

The epithelial to mesenchymal transition (EMT) induces loss of cell epithelial phenotype and has been initially described in the process of embryonic development (1). The EMT process is also a hallmark of several human cancers and as EMT progresses tumor cells become motile and increase their aggressiveness (2-4). Oral cancer and more specifically oral squamous cell carcinoma (OSCC) is a very common malignancy. It is characterized by high propensity to recurrence and metastasis and a relatively modest 5-year survival rate. Approximately 40 to $50 \%$ of OSCC recurrence is believed to occur in part due to EMT. Differentiated epithelial cancer cells achieve a dedifferentiated mesenchymal appearance by EMT along with the capacity to dissociate from each other and migrate (5).

SLUG and SNAIL are the main transcriptional repressors of E-cadherin and are considered the principal mediators of EMT (5-7). Upregulation of the mesenchymal intermediate filament proteins $\alpha$-SMA and Vimentin is also a typical event in the course of EMT, leading to disturbed epithelial integrity $(8,9)$.

EMT occurs only in certain types of cancer cells that are localized predominantly at the tumor front, while other cancer cells retain their epithelial traits. Therefore, the transient nature of EMT and the heterogeneity of the degree of dedifferentiation pose a challenge for the establishment of appropriate in vivo studies (10). Recently, a strong association between EMT and cancer stem cells (CSCs) has also been revealed. It was shown that CSCs represent a plastic state of tumor cells undergoing EMT, induced either by cell-intrinsic and/or microenvironment-associated signals (11). In addition, previous studies have shown the presence of CSCs in the tumor margins (12). Therefore, the current study examined whether EMT was present in that specific area. EMT has been studied in the margin tissue of a limited number of cancers [breast (13), colon (14), lung (15)] but not in the resection margins of oral cancer, although it is well known that the histological and 
molecular status of the margins are determinants of tumor behavior $(16,17)$.

The present study aimed to investigate OSCCs and their resection margins in terms of mRNA expression of the EMT markers Vimentin, $\alpha$-SMA, SLUG and SNAIL in tumor and margin primary cell cultures during specific cell passages. Moreover, the present study investigated EMT-associated features, including the clonal, proliferative and migratory potential of tumor and margin cells.

\section{Materials and methods}

Patients and tissues. In order to investigate the incidence of EMT in OSCC, tumor and margin tissues of 6 patients ( 2 females and 4 males, average age 59.5 $\pm 9.33,3$ tongue and 3 floor of the mouth tumors) diagnosed with OSCC were obtained at the Clinic of Maxillofacial Surgery of the School of Dental Medicine at the University of Belgrade. The samples were processed by immunostaining. Deparaffinization of $5-\mu \mathrm{m}$ tissue sections was performed in xylene. The process was repeated two times for $5 \mathrm{~min}$. The sections were processed by hydration with graded ethanol $(100,96,80,70,50 \%) 2 \mathrm{x}$ for $5 \mathrm{~min}$. Pretreatment was performed in $0.1 \mathrm{ml}$ citrate buffer (pH 6.0) for $20 \mathrm{~min}$ at $98^{\circ} \mathrm{C}$. The samples were incubated in $3 \% \mathrm{H}_{2} \mathrm{O}_{2}$ for $5 \mathrm{~min}$ and rinsed in Tris-buffered saline solution. This was followed by application of the UV blocker for $5 \mathrm{~min}$. The samples were incubated with rabbit polyclonal antibodies for Vimentin, $\alpha$-SMA, SNAIL and SLUG (Thermo Fisher Scientific) for $20 \mathrm{~min}$. Following rinsing for $5 \mathrm{~min}$, the samples were analyzed with Quatro amplifier for $10 \mathrm{~min}$, Quatro polymer for $10 \mathrm{~min}, \mathrm{DAB}$ quatro for $5 \mathrm{~min}$ and finally counterstained with hematoxylin for $2 \mathrm{~min}$. Between all these phases, the samples were rinsed for $5 \mathrm{~min}$. The images were captured by the Olympus DP70 camera and the Olympus BX50 microscope (Olympus).

Cell and tissue culture. OSCC tumor and margin tissues were obtained immediately prior to the surgery. Tumor margins were obtained $5 \mathrm{~mm}$ from the edges of the tumor. The SCC-25 cancer cell line (ATCC ${ }^{\circledR}$ CRL-16 28 ${ }^{\mathrm{TM}}$ ) was used as the negative control sample. Fibroblasts isolated from gingiva of heathy donors were used as the positive control sample. The present study was approved by the Institutional Ethics Committee (no. 36/31) and conducted in accordance with the Declaration of Helsinki. The patients were informed of the study protocol and signed a written informed consent form. The histopathological diagnosis of OSCC was established in accordance with the World Health Organization (WHO) guidelines and the tumor staging was performed using the TNM classification. Margin samples were obtained at least $5 \mathrm{~mm}$ from the edges of the surgical defects following primary tumor excision and the absence of neoplastic cells was histologically confirmed. Dulbecco's modified Eagle's medium (DMEM) supplemented with $20 \%$ fetal bovine serum (FBS) and $100 \mathrm{U} / \mathrm{ml}$ penicillin-100 $\mu \mathrm{g} / \mathrm{ml}$ streptomycin (Sigma-Aldrich; Merck KGaA) was used for tissue culture. The tissue samples were homogenized with blades into $1 \mathrm{~mm}^{3}$ pieces and washed 3 times with PBS to remove loosely bound cells, as previously described. An explant-cell culture system $(12,18)$ was carried out with periodical removal of fibroblasts using differential trypsiniza- tion (19). The cells were grown in DMEM supplemented with $10 \% \mathrm{FBS}$ and $100 \mathrm{U} / \mathrm{ml}$ penicillin- $100 \mu \mathrm{g} / \mathrm{ml}$ streptomycin in T75 cell culture flasks. A 1:1 mixture of DMEM and Ham's F12 medium supplemented with $400 \mathrm{ng} / \mathrm{ml}$ hydrocortisone and $10 \%$ FBS was used for the SCC-25 cell culture. SCC-25 cells used for the study were at the 10th passage. The cells were preserved at $37^{\circ} \mathrm{C}$ in a humidified atmosphere containing $5 \% \mathrm{CO}_{2}$. The medium was changed every 2-3 days and the cells were passaged prior to reaching $80 \%$ confluence. A total of $5 \times 10^{5}$ cells were plated for the next passage. The tissue cells were designated as tumor tissue (Tu) and margin tissue (M) cells. These cells were obtained following the first (P1) and the fifth (P5) passage (Fig. 1). All experiments were performed in triplicate and repeated for three times.

RNA extraction and reverse transcription-quatintitative $(R T-q) P C R$. Total RNA was extracted from OSCC and margin cells, SCC-25 and fibroblasts $\left(10^{6}\right.$ cells per tube) using TRIzol (Invitrogen; Thermo Fisher Scientific, Inc.). Complementary DNA was prepared using the Revert Aid First Strand cDNA synthesis kit (Thermo Fisher Scientific, Inc.) according to the manufacturer's instructions. Subsequently, RT-qPCR analysis was performed on a Line Gene-K Fluorescence Real-time PCR Detection System (Bioer Technology, Inc.) using Maxima ${ }^{\mathrm{TM}}$ SYBR-Green/ROX qPCR Master Mix (Thermo Fisher Scientific Inc.). The expression of GAPDH (housekeeping gene) was used for normalization. The $2^{-\Delta \Delta c t}$ method was used for the relative quantification of gene expression as described by Livak and Schmittgen (20). All oligonucleotide primers were purchased from Sigma-Aldrich; Merck KGaA and their sequences are provided in Table I.

Protein extraction and western blotting. The cells were resuspended in RIPA lysis buffer $(50 \mathrm{mM}$ Tris- $\mathrm{HCl} \mathrm{pH} 7.6$, $150 \mathrm{mM}$ sodium chloride, $1 \%$ Triton $\mathrm{X}-100,1 \%$ sodium deoxycholate, $0.1 \%$ sodium dodecyl sulphate, $2 \mathrm{mM}$ EDTA and $50 \mathrm{mM}$ sodium fluoride). A protease inhibitor cocktail (Pierce Biotechnology, Inc.) and sodium orthovanadate (Sigma-Aldrich; Merck KGaA) were added to the lysis buffer prior to use. Western blotting was conducted by running equal amount protein samples on polyacrylamide gels. The proteins were transferred from the gels to polyvinylidene difluoride (PVDF) membrane. The experiment was performed in duplicate. The membranes were first probed with primary antibodies against anti-vimentin (Santa Cruz Biotechnology, Inc.; cat. no. sc-32322, 1:200), then stripped with Restore Western Blot Stripping Buffer (cat. no. 21059, Thermo Fisher Scientific, Inc.) according to manufacture's instructions. After that, the membranes were probed with anti-alpha smooth muscle actin antibody (Abcam; cat. no. ab7817, 1:300). After stripping again with same buffer, membranes were probed with $\beta$-actin $(\mathrm{R} \& \mathrm{D}$; cat. no. MAB8929, 1:6,000). Peroxidase-conjugated goat antimouse immunoglobulin (Thermo Fisher Scientific, Inc.; cat. no. 31430, 1:5,000) was used as the secondary antibody. Hyperfilm was used to visualize the protein expression by a chemiluminescent reagent kit (Abcam; cat. no. ab79907) according to the manufacturer's instructions. The content of Vimentin and $\alpha$-SMA in the tumor and margin cell cultures was estimated by densitometry of the scanned immunoblot 
A

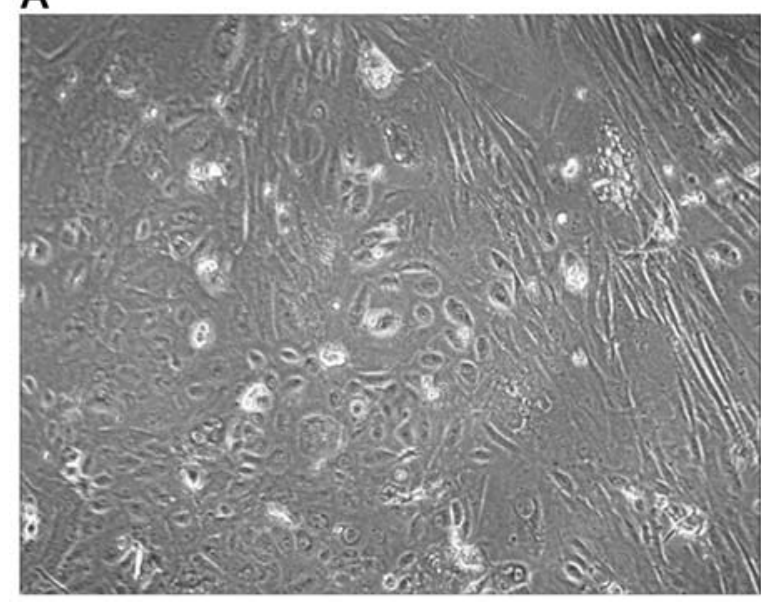

B

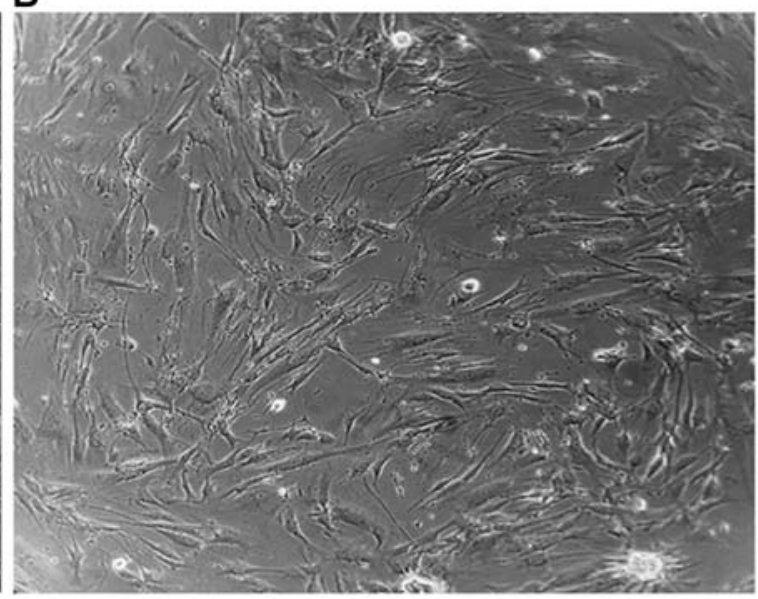

Figure 1. Representative micrographs of (A) tumor and (B) margin cells of the fifth passage (magnification, $\mathrm{x} 40$ ).

Table I. Primers used for expression analysis.

\begin{tabular}{ll}
\hline Primer name & \multicolumn{1}{c}{ Sequence $\left(5^{\prime} \rightarrow 3^{\prime}\right)$} \\
\hline $\begin{array}{l}\text { Vimentin } \\
\text { Forward } \\
\text { Reverse } \\
\alpha-\text { SMA }\end{array}$ & TCTACGAGGAGGAGATGCGG \\
Forward & CAATGGCTCTGGGCTCTGTAAG \\
Reverse & TGTTCTATCGGGTACTTCAGGGTC \\
SNAIL & \\
Forward & ACCACTATGCCGCGCTCTT \\
Reverse & GGTCGTAGGGCTGCTGGAA \\
SLUG & \\
Forward & TGTTGCAGTGAGGGCAAGAA \\
Reverse & GACCCTGGTTGCTTCAAGGA \\
GAPDH & \\
Forward & TCATGACCACAGTCCATGCCATCA \\
Reverse & CCCTGTTGCTGTAGCCAAATTCGT \\
\hline
\end{tabular}

bands using the Image Lab (Bio-Rad) software and normalized to the $\beta$-actin protein density.

Colony formation assay. The cells were seeded in the 12-well plate at a concentration of $10^{4}$ cells per well in DMEM supplemented with $10 \%$ FBS. Tumor and margin cells were incubated $\left(37^{\circ} \mathrm{C}, 5 \% \mathrm{CO}_{2}\right)$ and the number of live cells was counted following 3, 5, and 7 days of incubation period.

A total of 200 cells were plated per well in $32 \mathrm{~mm}$-wide plates and cultured in $1.5 \mathrm{ml}$ of DMEM supplemented with $10 \%$ FBS for 7 and 14 days. The cell colonies were washed with PBS, fixed in formalin for $5 \mathrm{~min}$ and stained with $0.05 \%$ crystal violet for $30 \mathrm{~min}$ at room temperature. Following removal of the dye, the colonies with more than 50 cells were counted as positive using the ImageJ software. The results are presented as colony formation efficiency (21) and as the ratio between the number of colonies formed and the number of seeded cells.
Wound healing assay. A wound healing assay was conducted to detect cell motility (22). Single-cell suspensions of margins and tumors were added to 24 -well plates $\left(2 \times 10^{5}\right.$ cells/well in $0.7 \mathrm{ml}$ of DMEM supplemented with $10 \%$ FBS) and cultured for 4-5 days to a confluence of approximately $80 \%$. The monolayer was scratched with a sterile $1.2 \mathrm{~mm}$-wide pippete tip across the center of the well in a straight line to cause a wound in the confluent cell monolayer. Subsequently, the wells were washed with PBS and grown in the incubator with serum-free DMEM $\left(37^{\circ} \mathrm{C}, 5 \% \mathrm{CO}_{2}\right)$. A BIB-100/T inverted microscope and HDCE-90D camera with Scope Image 9.0 software (BOECO Germany) were used to measure the closest area of the scratch. Cell migration was calculated by monitoring the entire movement of the monolayer. The shortest distance was measured between the separated monolayers and divided with time. The cell speed, measured in $\mu \mathrm{m} / \mathrm{h}$, was calculated for all $24 \mathrm{~h}$ intervals until the scratch area was closed, as follows:

$$
S(I d a y)=\frac{d(0 h)-d(24 h)}{24} S(I I d a y)=\frac{d(24 h)-d(48 h)}{24}
$$

$$
\begin{gathered}
\qquad(\text { IIIday })=\frac{d(48 h)-d(72 h)}{24} \\
\text { The average cell speed was } S=\frac{S(\text { Iday })+S(\text { IIday })+S(\text { IIIday })}{3}
\end{gathered}
$$

Statistical analysis. One-way or two-way ANOVA tests, with Tukey's post hoc comparison were performed in the present study, after checking the distribution normality by Kolmogorov-Smirnov normality test. The values are presented as mean \pm SD. Statistical significance was set at $\mathrm{P}<0.05$. The software package GraphPad Prism version 6 was used for the analyses (GraphPad Software, Inc.).

\section{Results}

Vimentin, $\alpha-S M A, S L U G$ and SNAIL are expressed in tumor and margin samples. Prior to undertaking mRNA expression analyses in cell cultures, the presence of EMT markers was determined by immunohistochemical analysis of fixed tissue specimens. Tumors and resection margins were used from 

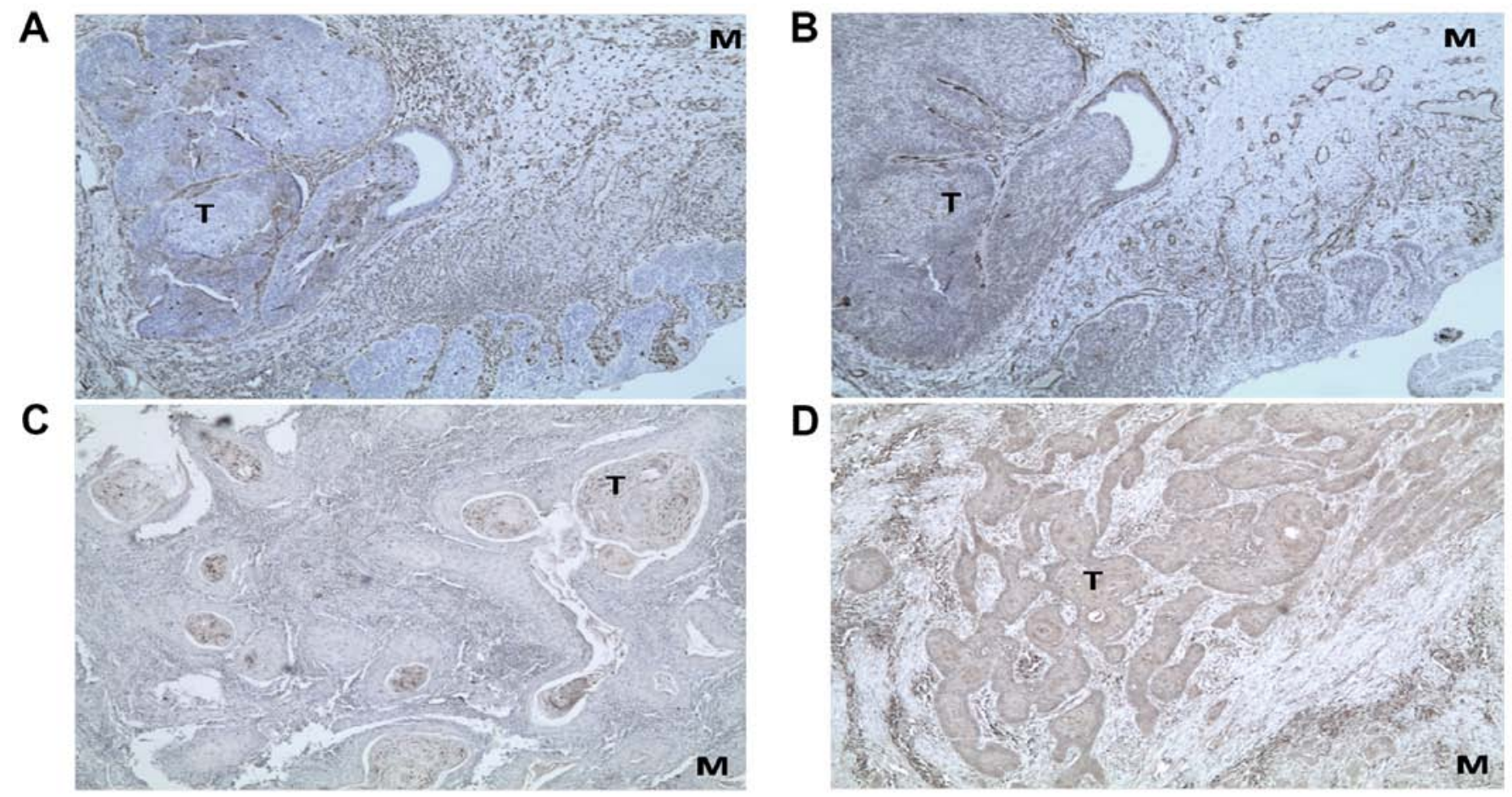

Figure 2. Immunostaining of epithelial to mesenchymal transition markers. (A) vimentin, (B) $\alpha$-smooth muscle actin, (C) SLUG and (D) SNAIL were assessed (magnification,x50).T, tumor; M, margin.

patients for establishing cell cultures. A clear immunostaining could be observed for all the markers (Vimentin, $\alpha$-SMA, SLUG and SNAIL) in the tumors as well as in their margins. The representative micrographs are shown in Fig. 2.

RT-qPCR analysis was used to detect the expression levels of the epithelial to mesencymal transition markers (Vimentin, $\alpha$-SMA, SLUG and SNAIL) in both tumor and margin cells. The expression levels in these two types of cells were different. However, no significanct difference was noted $(\mathrm{P}>0.05)$. Vimentin was the marker that exhibited the highest levels of expression in both OSCC and margin cells and as expected in fibroblast cultures. However, these results were not noted in the oral cancer cell line SCC-25, which maintained its epithelial characteristics during cultivation. The levels of Vimentin mRNA were higher in tumor and margin cells at the beginning of cultivation (1st passage) than in the cells of the 5th passage. However, the differences noted were not significant. In contrast, the relative gene expression levels of $\alpha$-SMA (in margin cultures) and SNAIL (in tumor cultures) were higher in the 5th passage compared with those of the 1st passage $(\mathrm{P}<0.05)$ (Fig. 3). This trend was also noted in the expression levels of SLUG in tumor cells.

In order to confirm the findings obtained by qPCR analysis, the protein expression levels of the two EMT markers Vimentin and $\alpha$-SMA were examined. Protein expression was in line with mRNA levels, although without statistically significant differences between passages (Fig. 4).

The proliferation rate of tumor and margin cells depends on their passage number. The number of cells was increased during the 7-day assay duration, with the exception of the 5th passage margin cells. The differences noted between tumor and margin cells were evident in the 5th passage of cells.
Tumor cells exhibited higher proliferative potential (Fig. 5A). Generally, in both tumor and margin cells, the proliferation rates decreased from the 1 st to the 5 th passage.

The differences noted with regard to the colony formation ability were statistically significant from the 7 th to the 14th day $(\mathrm{P}<0.05)$. The number of colonies formed by the tumor cells (1.25 and 15.25 following 7 and 14 days of incubation, respectively), and margin cells (2.33 and 17.67 following 7 and 14 days of incubation, respectively) was similar. The colony formation efficiency is provided in Fig. 5B. No significant differences were noted in that parameter during different passages. The motility of the tumor and margin cells did not exhibit significant differences between cell passages (Fig. 6). The average value of cell speed during the $72 \mathrm{~h}$ period is given in Fig. 6Q.

\section{Discussion}

The poor prognosis of OSCC is mainly caused due to the high recurrence and metastasis rates and remains a significant medical challenge, regardless of the advances in diagnostic and therapeutic procedures $(23,24)$. Recent studies have recognized EMT as a critical process during tumor cell invasion of the surrounding stroma, which may explain specific essential steps leading to metastasis and tumor recurrence.

The present study hypothesized that EMT occurs preferentially at the tumor margin, which is the site of vessel -invasion $(13,14,25)$. Consequently, margin tissue samples were used in addition to resected OSCC samples in order to establish cell cultures and assess their corresponding EMT-associated features. All EMT markers (Vimentin, $\alpha$-SMA, SNAIL, SLUG) were expressed in both types of cells 

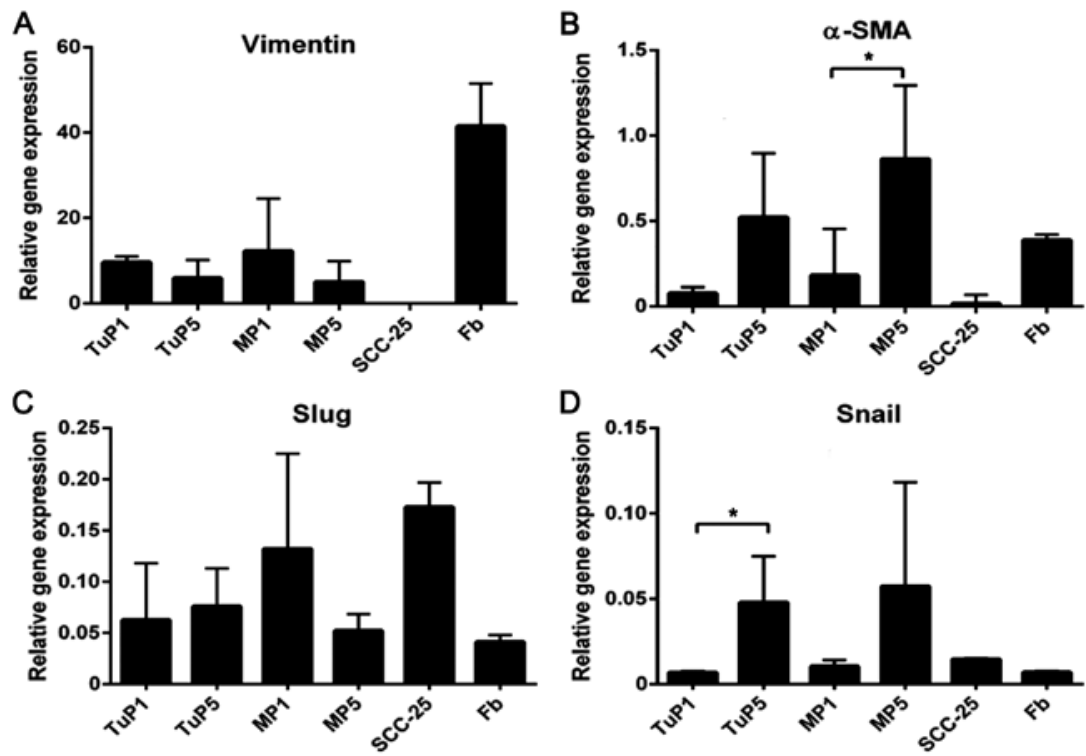

Figure 3. Expression of epithelial to mesenchymal transition-associated markers in tumor, margin and control cell cultures. (A) Vimentin, (B) $\alpha$-SMA, (C) Slug and (D) Snail expression. The SCC-25 cancer cell line was used as a negative control sample, whereas Fb isolated from gingiva were used as positive control samples. Data are presented as the mean \pm standard deviation. " $\mathrm{P}<0.05$ as indicated. EMT, epithelial to mesenchymal transition; Fb, fibroblasts; SMA, smooth muscle actin; TuP1, tumor cells derived from the first passage; TuP5, tumor cells of the fifth passage; MP1, margin cells of the first passage; MP5, margin cells of the fifth passage.
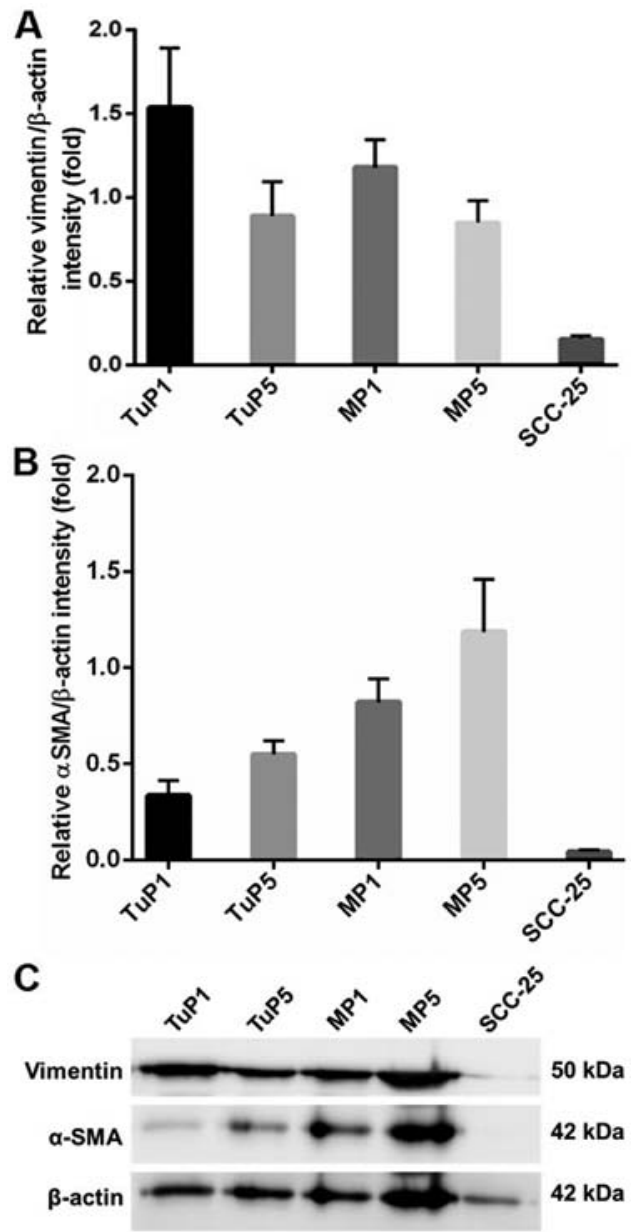

Figure 4. Western blot analysis. (A) vimentin and (B) $\alpha$-SMA expression. (C) Represenetative western blot analysis. The SCC-25 cancer cell line was used as a control. Data presented as the mean \pm standard deviation. TuP, tumor tissue passage; MP, margin tissue passage. SMA, smooth muscle actin; TuP1, tumor cells derived from the first passage; TuP5, tumor cells of the fifth passage; MP1, margin cells of the first passage; MP5, margin cells of the fifth passage.
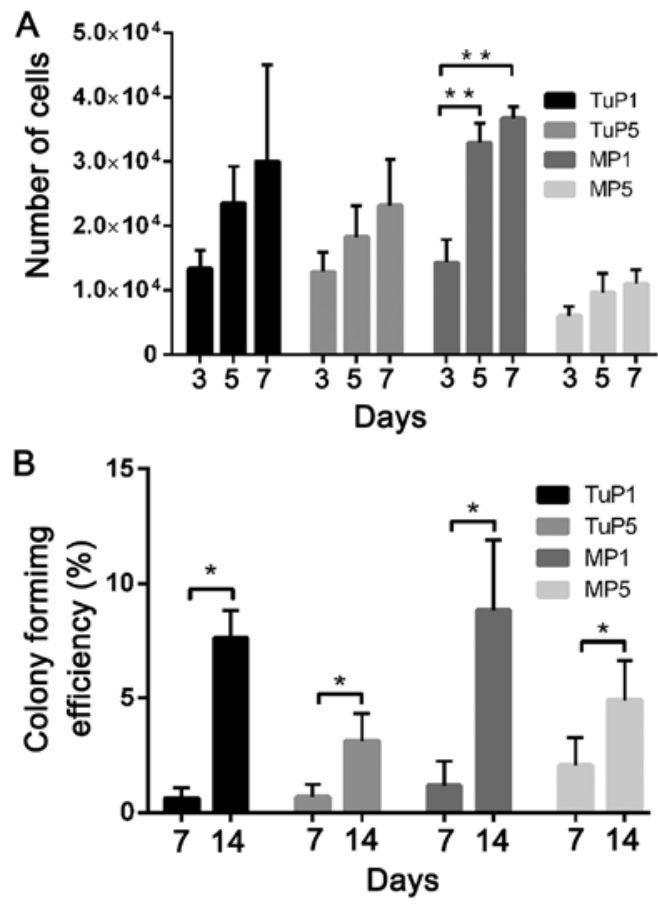

Figure 5. Colony formation and cell proliferation assays. (A) The number of viable cells during 7 day cultivation. (B) The number of cell colonies formed on the 7th and 14th day of culture, as determined by a colony formation assay; ${ }^{*} \mathrm{P}<0.05$ and ${ }^{* *} \mathrm{P}<0.005$ as indicated. TuP1, tumor cells derived from the first passage; TuP5, tumor cells of the fifth passage; MP1, margin cells of the first passage; MP5, margin cells of the fifth passage.

(tumor and margin) at various levels. The expression levels of these markers did not exhibit significant differences between cancer and margin cells, although, they were significantly higher in the margin tissues.

In the present study, high levels of Vimentin mRNA were detected in both tumor and margin cell cultures. The migratory 

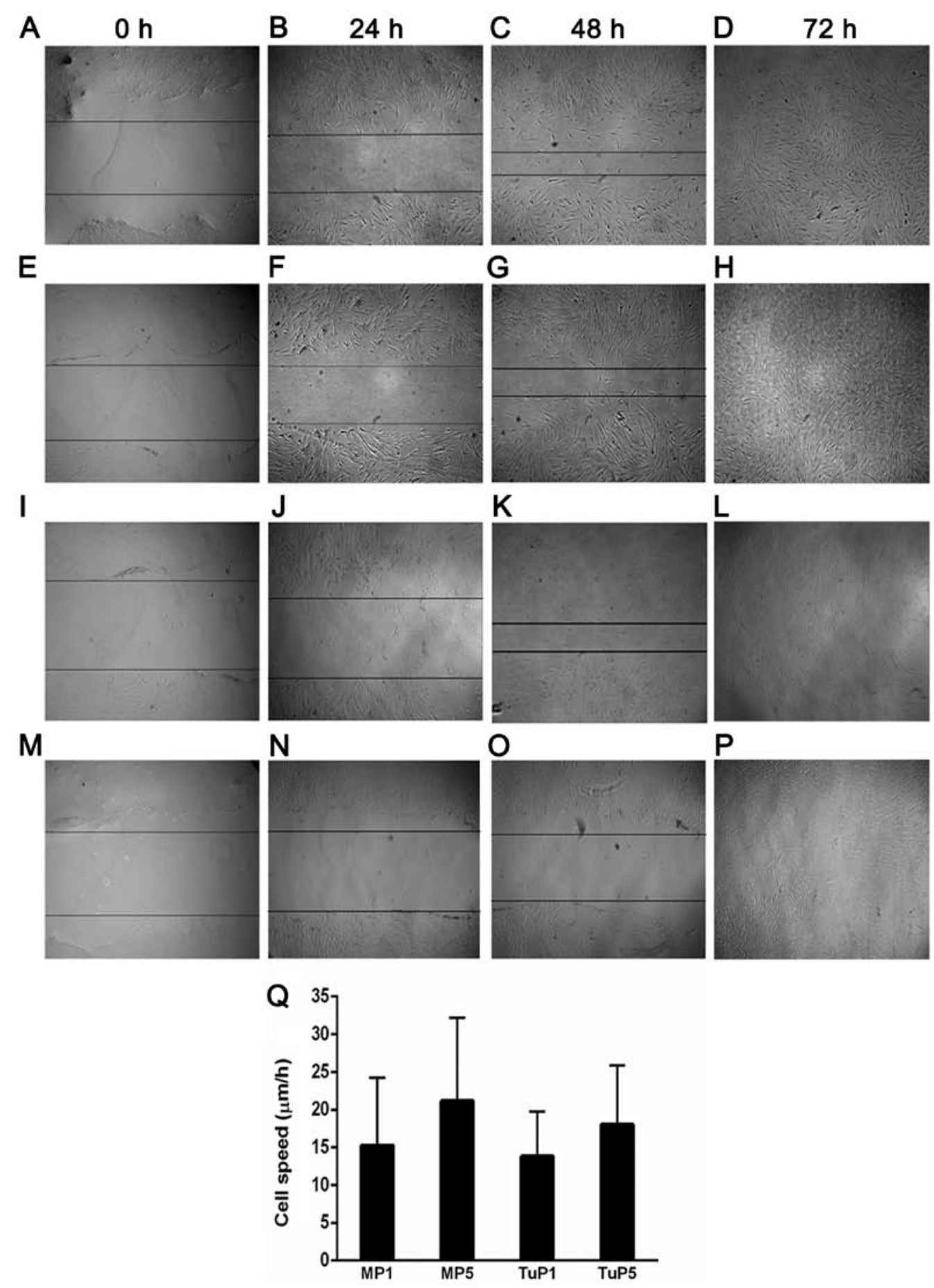

Figure 6. Representative micrographs of cell migration. Tumor cells of the first passage at (A) $0 \mathrm{~h}$, (B) $24 \mathrm{~h}$, (C) $48 \mathrm{~h}$ and (D) $72 \mathrm{~h}$ after the scratch. Tumor cells of the fifth passage at (E) $0 \mathrm{~h},(\mathrm{~F}) 24 \mathrm{~h},(\mathrm{G}) 48 \mathrm{~h}$ and (H) $72 \mathrm{~h}$ after the scratch. Margin cells of the first passage at (I) $0 \mathrm{~h},(\mathrm{~J}) 24 \mathrm{~h},(\mathrm{~K}) 48 \mathrm{~h}$ and (L) $72 \mathrm{~h}$ after the scratch. Margin cells of the fifth passage at $(\mathrm{M}) 0 \mathrm{~h},(\mathrm{~N}) 24 \mathrm{~h},(\mathrm{O}) 48 \mathrm{~h}$ and $(\mathrm{P}) 72 \mathrm{~h}$ after the scratch. (Q) Average migration was subsequently calculated. Magnification, $\mathrm{x} 40$. TuP1, tumor cells derived from the first passage; TuP5, tumor cells of the fifth passage; MP1, margin cells of the first passage; MP5, margin cells of the fifth passage; $d$, day.

potential of the two cell types was highly concordant, probably due to similar expression levels of Vimentin. Increased expression levels of Vimentin are associated with cancer progression. This protein is an indicator of high cell migratory activity $(8,26)$ which is in agreement with the results of the present study.

One of the major factors affecting EMT marker expression was cell passaging. The expression levels of the markers were increased during cell passages and significant differences were established for $\alpha$-SMA and SNAIL in both types of cells. This finding can tentatively be explained by cell culture enrichment with cancer stem cells during passages as determined by the increase in the expression levels of CSC markers, such as CD44, CD133, Oct4, Sox 2 and Nanog (12). This in turn reflects to a certain extent the clonal evolution of tumors and the increase of aggressiveness during tumor progression. It was previously shown that SNAIL exerted an important role in inducing and maintaining CSC-like properties by EMT induc- 
tion in OSCC (27). Alternatively, the cells in the culture may undergo transdifferentiation during passaging, progressively acquiring the mesenchymal phenotype. This phenomenon has been previously described in ovarian cancer cells, which can synthesize collagen I and II, while gradually losing the expression of cytokeratin during passaging (28).

The proliferation rates of tumor and margin cells was decreased over the passaging period and this finding was in accordance with Vega et al (29) and Mejlvang et al (30) who demonstrated that the activation of EMT reduces cell proliferation. In the present study, tumor and tumor margin cells exhibited similar abilities to form colonies, which was also accompanied by relevant EMT-associated features (31). This similar capacity to form colonies was in accordance with the relative homogenous expression of the EMT markers analyzed in tumor and margin samples. These findings provide additional evidence in favor of the concept that EMT is present at multiple sites within the tumor, as previously hypotesized $(6,32)$. A recent study further demonstrated a characteristic pattern of expression for the proteins TWIST1, SNAI1, SNAI2 and ZEB1 in the center of primary breast tumors and their margins (33). Cancer 'self-seeding' ability may be another explanation for the remarkable phenotypic similarities of cancer and margin cells (34).

The data presented in the present study suggest that the EMT markers Vimentin, $\alpha$-SMA, SNAIL and SLUG were similarly expressed in tumor and margin cells of OSCC and that cell passaging increased their expression levels. With the exception of certain minor differences, the parameters proliferation rate, clonal ability, and migratory capacity were similar in the cells originating from tumors and resection margins, which suggested the importance of margin pathological status in terms of tumor aggressiveness.

\section{Acknowledgements}

Not applicable.

\section{Funding}

The present study was supported by the Ministry of Education, Science and Technological Development, Republic of Serbia (grant nos. 175075 and III 41027) and the Ministry of Foreign Affairs of Italy (grant no. PGR02954).

\section{Availability of data and materials}

The datasets used and/or analyzed during the current study are available from the corresponding author on reasonable request.

\section{Authors' contributions}

ML and JM conceived and designed the current study. ML, MM, BT, DJ and FB performed RT-qPCR. SM, ZT and TS performed histology, immunohistochemistry and western blotting. ML, MM, BT, DJ and DT performed cell culture. ML, MM, SM, ZT, DJ, GD and FB analyzed and interpreted the data. LM, JD and MD aquired clinical data and samples. ML, GD and JM wrote the manuscript. All authors revised the manuscript.

\section{Ethics approval and consent to participate}

The current study was approved by the Institutional Ethical Committee of the School of Dental Medicine (approval no. 36/31). Written informed consent was obtained from all patients.

\section{Patient consent for publication}

All patients signed an informed consent to participate in the study that included patients' agreement to the publication of their data/images on condition of anonymity.

\section{Competing interests}

The authors declare that they have no competing interests.

\section{References}

1. Maeng YI, Kim KH, Kim JY, Lee SJ, Sung WJ, Lee CK, Park JB and Park KK: Transcription factors related to epithelial mesenchymal transition in tumor center and margin in invasive lung adenocarcinoma. Int J Clin Exp Pathol 7: 4095-4103, 2014.

2. Acloque H, Adams MS, Fishwick K, Bronner-Fraser M and Nieto MA: Epithelial-mesenchymal transitions: The importance of changing cell state in development and disease. J Clin Invest 119: 1438-1449, 2009.

3. Kalluri R and Weinberg RA: The basics of epithelial-mesenchymal transition. J Clin Invest 119: 1420-1428, 2009.

4. Lim J and Thiery JP: Epithelial-mesenchymal transitions: Insights from development. Development 139: 3471-3486, 2012.

5. Thiery JP: Epithelial-mesenchymal transitions in tumour progression. Nat Rev Cancer 2: 442-454, 2002.

6. Moreno-Bueno G, Portillo F and Cano A: Transcriptional regulation of cell polarity in EMT and cancer. Oncogene 27: 6958-6969, 2008.

7. Peinado H, Olmeda D and Cano A: Snail, ZEB and bHLH factors in tumour progression: An alliance against the epithelial phenotype? Nat Rev Cancer 7: 415-428, 2007.

8. Misra A, Pandey C, Sze SK and Thanabalu T: Hypoxia activated EGFR signaling induces epithelial to mesenchymal transition (EMT). PLoS One 7: 49766, 2012.

9. Liang L, Zeng M, Pan H, Liu H and He Y: Nicotinamide $\mathrm{N}$-methyltransferase promotes epithelial-mesenchymal transition in gastric cancer cells by activating transforming growth factor- $\beta 1$ expression. Oncol Lett 15: 4592-4598, 2018.

10. Krisanaprakornkit $S$ and Iamaroon A: Epithelial-mesenchymal transition in oral squamous cell carcinoma. ISRN Oncol 2012: 681469, 2012.

11. Zhang Z, Dong Z, Lauxen IS, Filho MS and Nor JE: Endothelial cell-secreted EGF induces epithelial to mesenchymal transition and endows head and neck cancer cells with stem-like phenotype. Cancer Res 74: 2869-2881, 2014.

12. Lazarevic M, Milosevic M, Trisic D, Toljic B, Simonovic J, Nikolic N, Mikovic N, Jelovac D, Petrovic M, Vukadinovic M and Milasin J: Putative cancer stem cells are present in surgical margins of oral squamous cell carcinoma. J BUON 23: 1686-1692, 2018.

13. Nassar A, Radhakrishnan A, Cabrero IA, Cotsonis GA and Cohen C: Intratumoral heterogeneity of immunohistochemical marker expression in breast carcinoma: A tissue microarray-based study. Appl Immunohistochem Mol Morphol 18: 433-441, 2010.

14. Brabletz T, Jung A, Reu S, Porzner M, Hlubek F, Kunz-Schughart LA, Knuechel R and Kirchner T: Variable beta-catenin expression in colorectal cancers indicates tumor progression driven by the tumor environment. Proc Natl Acad Sci 98: 10356-10361, 2001.

15. Zacharias M, Brcic L,Eidenhammer S and Popper H: Bulk tumour cell migration in lung carcinomas might be more common than epithelial-mesenchymal transition and be differently regulated. BMC Cancer 18: 717, 2018.

16. Eljabo N, Nikolic N, Carkic J, Jelovac D, Lazarevic M, Tanic N and Milasin J: Genetic and epigenetic alterations in the tumour, tumour margins, and normal buccal mucosa of patients with oral cancer. Int J Oral Maxillofac Surg 47: 976-982, 2018. 
17. Jelovac DB, Tepavčević Z, Nikolić N, Ilić B, Eljabo N, Popović B, Čarkić J, Konstantinović V, Vukadinović M, Miličić B and Milašin J: The amplification of c-erb-B2 in cancer-free surgical margins is a predictor of poor outcome in oral squamous cell carcinoma. Int J Oral Maxillofac Surg 45: 700-705, 2016.

18. Mitra A, Mishra L and Li S: Technologies for deriving primary tumor cells for use in personalized cancer therapy. Trends Biotechnol 31: 347-354, 2013.

19. Jones JC: Reduction of contamination of epithelial cultures by fibroblasts. CSH Protoc: pdb.prot4478, 2008.

20. Livak KJ and Schmittgen TD. Analysis of relative gene expression data using $r$, eal-time quantitative PCR and the 2(T) (-Delta Delta C) method. Methods 25: 402-408, 2001.

21. Trivanović D, Kocić J, Mojsilović S, Krstić A,Ilić V, Djordjević IO, Santibanez JF, Jovcić G, Terzić M and Bugarski D: Mesenchymal stem cells isolated from peripheral blood and umbilical cord Wharton's jelly. Srp Arh Celok Lek 141: 178-186, 2013.

22. Wong K, Rubenthiran U and Jothy S: Motility of colon cancer cells: Modulation by CD44 isoform expression. Exp Mol Pathol 75: 124-130, 2003.

23. Feller LL, Khammissa RR, Kramer BB and Lemmer JJ: Oral squamous cell carcinoma in relation to field precancerisation: Pathobiology. Cancer Cell Int 13: 31-39, 2013.

24. Zaravinos A: The regulatory role of MicroRNAs in EMT and cancer. J Oncol 2015: 865816, 2015.

25. Kurihara K, Isobe T, Yamamoto G, Tanaka Y, Katakura A and Tachikawa T: Expression of BMI1 and ZEB1 in epithelial-mesenchymal transition of tongue squamous cell carcinoma. Oncol Rep 34: 771-778, 2015.

26. Qin X, Yan M, Li R, Ye D, Zhang J, Xu Q, Feng Y, Sun Q, Jiang C and Chen W: Identification and characterization of a highly metastatic epithelial cancer cell line from rat tongue cancer. Arch Oral Biol 95: 58-67, 2018.

27. Ota I, Masui T, Kurihara M, Yook JI, Mikami S, Kimura T, Shimada K, Konishi N, Yane K, Yamanaka T and Kitahara T: Snail-induced EMT promotes cancer stem cell-like properties in head and neck cancer cells. Oncol Rep 35: 261-266, 2016.
28. Van Marck VL and Bracke ME: Epithelial-mesenchymal transitions in human cancer. Madame Curie Bioscience Database, Landes Bioscience, Austin, 2000.

29. Vega S, Morales AV, Ocaña OH, Valdés F, Fabregat I and Nieto MA: Snail blocks the cell cycle and confers resistance to cell death. Genes Dev 18: 1131-1143, 2004.

30. Mejlvang J, Kriajevska M, Vandewalle C, Chernova T, Sayan AE, Berx G, Mellon JK and Tulchinsky E: direct repression of cyclin D1 by sip1 attenuates cell cycle progression in cells undergoing an epithelial mesenchymal transition. Mol Biol Cell 18: 4615-4624, 2007.

31. Mani SA, Guo W, Liao MJ, Eaton EN, Ayyanan A, Zhou AY, Brooks M, Reinhard F, Zhang CC, Shipitsin M, et al: The epithelial-mesenchymal transition generates cells with properties of stem cells. Cell 133: 704-715, 2008.

32. Martin TA, Goyal A, Watkins G and Jiang WG: Expression of the transcription factors snail, slug, and twist and their clinical significance in human breast cancer. Ann Surg Oncol 12: 488-496, 2005.

33. Alkatout I, Wiedermann M, Bauer M, Wenners A, Jonat W and Klapper W: Transcription factors associated with epithelial-mesenchymal transition and cancer stem cells in the tumor centre and margin of invasive breast cancer. Exp Mol Pathol 94: 168-173, 2013

34. Kim MY, Oskarsson T, Acharyya S, Nguyen DX, Zhang XH, Norton L and Massagué J: Tumor self-seeding by circulating cancer cells. Cell 139: 1315-1326, 2009.

This work is licensed under a Creative Commons Attribution-NonCommercial-NoDerivatives 4.0 International (CC BY-NC-ND 4.0) License. 